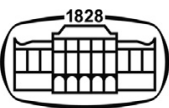

AKADÉMIAI KIADÓ

\title{
DHS Special Issue on “Ageing Humans, Ageing Societies"
}

\section{Á. KOLLER and Z. Z. NAGY}

\section{Developments in Health Sciences}

4 (2021) 1, 1

DOI:

$10.1556 / 2066.2021 .00046$

(C) 2021 The Author(s)

\section{FOREWORD}



\section{FOREWORD}

\section{Dear Reader,}

This issue of Developments in Health Sciences is dedicated to the topics of ageing humans and ageing societies. We think that these topics are very important and relevant because people live longer, but not necessarily healthier, which has a great impact on the life of individuals and societies. Already in 1991, the United Nation designated the first of October as the International Day of Older Persons.

Ever since the problems escalated. In Western societies (including Hungary) more than $20 \%$ of the population is 65 years old or older (in Hungary, the population above 65 years of age was $15.1 \%$ in $2001,16.7 \%$ in 2011 , and $19.3 \%$ in 2019). In addition to the physical disabilities, a recent report of the WHO reveals that more than 55 million people suffer from various forms of dementia and mental disabilities in the world.

Thus, to explore the challenges of ageing and its impacts on the lives of individuals and societies, in this issue we are publishing reviews summarising various aspects of ageing; from the genetic, epigenetic, molecular, and cellular mechanisms to the physiology, pathophysiology, and clinical aspects that are involved in the ageing of various organs, tissues (heart, vessels, kidney, eye, sensorimotor system, brain, etc.), and the whole organism. Moreover, perhaps one of the most important aspects of ageing, the psychological and mental effects are also discussed, along with sex-specific aspects as well, which has been less emphasised in the past.

Health is important not only for individual humans but on community levels; thus, it is important to know what effects ageing humans have on small and large communities, cities and countries, or even continents.

What problems should be prioritised, what prevention could be applied, and what should individuals and society do to develop and maintain healthy ageing?

We hope that this issue of Developments in Health Sciences will provide a window to the readers to have a look at the landscape of ageing humans and ageing societies.

Also, we hope that based on these publications a 3-day Conference will be organised next year under the auspices of Semmelweis University, Budapest, Hungary.

Put on your "glasses" and read the Developments in Health Sciences!

Ákos Koller, MD, PhD

Vice Editor-in-Chief

Zoltán Zsolt Nagy, med.habil, DSc, FEBO

Editor-in-Chief 